\title{
Cultivating Graduate Students: Techniques to Inspire Effective Research
}

\author{
David Braun $^{1}$, Linda Vanasupa ${ }^{2}$, Blair London ${ }^{2}$, Kevin Kingsbury ${ }^{3}$, Heather Smith ${ }^{4}$ \\ $1_{\text {Electrical Engineering Department, }}{ }^{2}$ Materials Engineering Department, \\ ${ }^{3}$ Department of Chemistry and Biochemistry, ${ }^{4}$ Statistics Department, \\ California Polytechnic State University, San Luis Obispo, CA 93407, U.S.A.
}

\section{ABSTRACT}

Each year, U.S. institutions grant well over 10,000 bachelor's degrees in science and engineering. However, only a small fraction of those students pursue graduate study. Many who do often experience great difficulty partly due to a lack of preparation for research: the nature of research is inherently foreign to those who are accustomed to studying course material and demonstrating their mastery of it by passing an exam. Carefully involving undergraduates in research can be an effective means for inspiring students to pursue graduate study. We have found that one can create a positive research experience for the student by implementing simple techniques. In this presentation, we present these practical techniques which include: Defining a manageable undergraduate research project; marketing the project to undergraduates; enabling effective record keeping in laboratory notebooks; focussing and directing research through efficient experimental designs. Along with these techniques, we will present examples-taken mainly from our Polymer Electronics Laboratory. We will also present the inherent pitfalls associated with these techniques.

\section{INTRODUCTION}

About a third of the students who begin doctorate degree programs in materials science and engineering do not complete their programs. Although we are not aware of a formal study that documents the reasons for attrition, past students often report that graduate study is "not what [they] expected." Many students expect graduate study to be a continuation of the undergraduate experience. This often involves mastering a series of concepts in order to pass a test. The test results provide immediate and concrete feedback on their performance. The test problems often have clear solutions. On the other hand, graduate research is focused on conducting tests (i.e., experiments) in order to study a problem. The solutions are neither clear nor close-ended, with few immediate indications of the success of one's work. This clearly builds a set of inaccurate expectations into the undergraduate about graduate study.

We feel that simulating the graduate experience for the undergraduate is a means of ensuring their success and informing their decisions to pursue (or not to purse) graduate research. Many institutions have created summer research programs under the Research Experiences for Undergraduates (REU) program funded by the National Science Foundation that serve to provide "simulated" research experiences. As a primarily undergraduate institution, we have to market research projects actively to encourage students to participate in REU's and other research. However, we have found a means to involve students in undergraduate programs. In doing so, we have developed three strategies to ensure the success of the students in their research. This paper describes the strategies and gives examples of how we used them in our program. 


\section{STRATEGY 1: DEFINE PROJECTS FOR SUCCESS}

Our thoughts about preparing appropriate projects arise from a Cal Poly perspective, namely, that of an institution who focuses primarily on undergraduate education and whose motto is “Learn by Doing.” In reading this article, you might think about how to translate them to your own institutions and research projects.

Viewed on a time horizon, for example, research projects suitable for Cal Poly might plan for a sooner completion than revolutionary research at a research institution, where many projects could take five years and longer to reach fruition. Cal Poly likes to collaborate with industry on projects that bear fruit in the two to five year niche, which works well for industry.

\section{Research Applications that Attract Interest}

Students enjoy and appreciate working on research that connects to exciting and useful applications. While numerous examples exist, this article highlights the example of semiconducting polymers as one that greatly motivates students and provides a fertile source for research projects. These materials excite students to form hypotheses and do research with their unique properties and multiple state-of-the-art applications. Semiconducting polymers blend several attractive material properties that enable inexpensive and unique applications. They offer the ability to tailor electronic and optical properties, as do many inorganic semiconductors. They also offer simultaneous control over mechanical and chemical features. Semiconducting polymer have the potential to deliver the next generation of flat and flexible image sensors, ink-jet printed integrated circuits, inexpensive solar cells, large area lighting and multimedia displays [1-9]. Such applications appeal to students and motivate them to pursue research in light-emitting diodes (LEDs), photodiodes, and transistors based on semiconducting polymers.

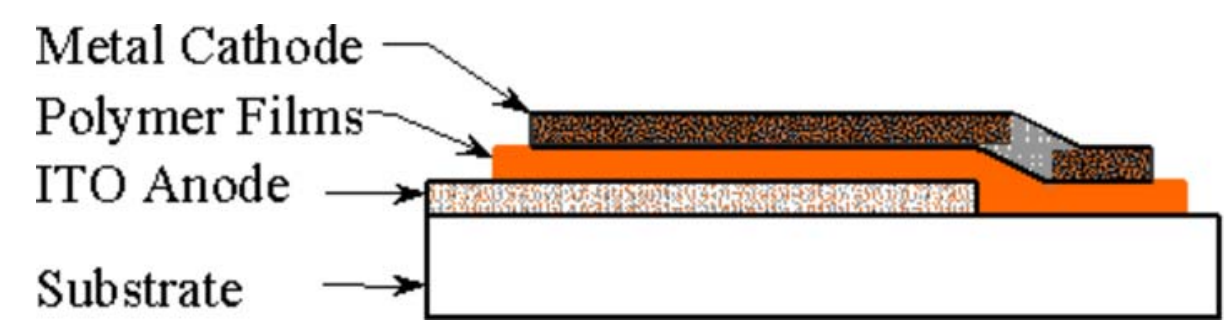

Figure 1. Polymer LED and Solar Cell Geometry. Applying a positive voltage to the anode relative to the cathode causes current to flow through the polymer film and light emission from the polymer film through the transparent bottom electrode and substrate. Devices made on plastic substrates can have flexible mechanical properties [3-5].

Using a polymer LED as an example illustrates several nice features of semiconducting polymers as a multidisciplinary research vehicle. A polymer LED consists essentially of a plastic film sandwiched between two electrodes. Figure 1 illustrates the device geometry. Applying a positive voltage to the anode relative to the cathode causes current to flow through the polymer film and light emission from the polymer film through the transparent bottom electrode and substrate. A photo-voltaic effect produces current from incident light. Undergraduate students can make samples, because they possess or 
can easily learn the skills to make such simple sandwich structures consisting of one or more polymer layers. The simple fabrication procedures give students access to sophisticated optoelectronic devices and useful applications. For more information about semiconducting polymers, research projects and course modules, see the lab web site, http://www.ee.calpoly.edu/ dbraun/polyelec/.

\section{Bite Size Management}

Recognizing the inherent differences between undergraduate and graduate students' abilities and background experiences gives faculty the responsibility to define projects appropriately. What might mean a one-month project for a graduate student, might require four to six months for an undergraduate. Fortunately, this is the time scale of a Cal Poly senior project. The professor must make up the depth of analysis and experience that undergraduate students may lack. The professor must also integrate the related undergraduate research projects into a meaningful research program. Recent Cal Poly projects have studied the efficiency of polymer LEDs and solar cells, built polymer LEDs on plastic substrates, designed and synthesized new materials for polymer devices, and simulated polymer matrix displays and image sensors [10-12]. In part, the success of such projects stems from matching students with compatible projects.

\section{STRATEGY 2: ATTRACT THE RIGHT STUDENTS}

Within Cal Poly's emphasis on undergraduate education, there exist a few avenues to incorporate research in the existing undergraduate curriculum. The capstone Senior Project required of all campus graduates is perhaps the most convenient route. Special Project courses also allow students to earn credit for research activities. Exposing students to research topics as part of a course can draw students into doing their own research. We have had great success in enticing students by integrating modules based on semiconducting polymers into a variety of courses. Exposure to the materials in course modules naturally sparks students to generate research questions of their own and motivates their further study. Table I lists course modules that generate student interest in semiconducting polymers.

MATE 345 considers the electronic, optical and magnetic properties of materials and forms part of the foundation of Materials Engineering. Since the energy gaps of some semiconducting polymers lie in the visible range, the three spectroscopy modules designed for this course literally allow students to see photoluminescence and electroluminescence.

Table I. Curriculum modules based on semiconducting polymers

\begin{tabular}{|l|l|}
\hline Course Number \& Title & Semiconducting Polymer Module(s) \\
\hline $\begin{array}{l}\text { MATE } 345 \\
\text { Electronic Properties of Materials } \\
\text { Laboratory }\end{array}$ & $\begin{array}{l}\text { Photoluminescence Spectroscopy } \\
\text { Electroluminescence Spectroscopy } \\
\text { Polymer Structure to Property Experiment }\end{array}$ \\
\hline $\begin{array}{l}\text { CHEM 447 } \\
\text { Polymers and Coatings Laboratory }\end{array}$ & $\begin{array}{l}\text { Semiconducting Polymer Synthesis } \\
\text { Polymer LED Fabrication and Test }\end{array}$ \\
\hline
\end{tabular}


CHEM 447 is a polymer synthesis laboratory, which builds the repertoire of techniques used to prepare and analyze a wide variety of organic polymers and coatings. A semiconducting polymer experiment such as the MEH-PPV synthesis [6] motivates the students to apply some of those techniques toward the synthesis and analysis of a semiconducting polymer that they then BUILD into a working electronic device such as a lightemitting diode. Students glean additional motivation from carrying an organic chemistry concept through to a working demonstration

In EE 422, Polymer Electronics Laboratory, students apply their knowledge of solid state device fabrication and characterization to build and analyze the performance of a solid state device based on a semiconducting polymer. Semiconducting polymers enable students to make and test devices large enough to be visible to the naked eye AND do so using simple and inexpensive fabrication techniques.

After fabrication, the student can operate the device by applying a voltage between the electrodes and observing light emission. The students gain a graphic illustration of charge injection into a semiconductor, charge transport, and the process of light emission from a semiconductor. Characterizing the electrical characteristics and intensity of light emission for various devices can spark a variety of creative experiments. For students who seek thorough understanding, the available research and patent literature on semiconducting polymers provides some answers and more questions. The above course modules have motivated several students to pursue research projects to apply their inquisitiveness to improve the performance of polymer devices. In their enthusiasm, students also advertise their research by word-of-mouth, infecting their friends with curiosity. Once a motivated student arrives to participate in a research project, the research proceeds more effectively if the student's skills match their eagerness.

\section{STRATEGY 3: EQUIP FOR PRODUCTION}

\section{Effective Laboratory Notebook Practices}

Much time can be lost repeating experiments and/or re-finding documents because of poorly kept records. An up-to-date, properly documented lab notebook can save the student hours upon hours. The strategies for effective notebooks include

- Lead by example-The advisor must be the one to demonstrate the effective use of the lab notebook. Students will notice and follow suit.

- Use always-Resist the temptation to keep records on a notepad or loose pieces of paper (or, God forbid, Post-it ${ }^{\mathrm{TM}}$ notes!). The lab notebook should be a constant presence in group meetings and visits to the lab. Data analyzed with the computer should be pasted into the lab notebook.

- Use professional notebooks-Purchase a lab notebook that is bound and has a grid for making graphs and has numbered pages (or add your own numbers). Do not use a spiral bound notebook that allows you to tear out pages or a loose-leaf notebook. Neither of these versions would be acceptable at a company that uses laboratory notebooks as a means of keeping official records.

- Review Regularly-By reviewing the contents of the notebooks regularly, the information becomes more valuable. Have group members countersign pages to give the students incentive to make the pages understandable.

- Keep up-to-date-Make sure that the table of contents is up-dated as new information is entered.

These strategies are simple but powerful ways to develop effective record-keeping habits. 


\section{Efficient Experimental Designs}

Approaching research can be like trying to navigate your way through a maze. You can help the student a great deal by directing him or her to

1. Formulate a statement of the problem that includes the factors that will affect the outcome and the response. For example, we had a student who wanted to study polymer light-emitting diodes. The first statement of the problem came in the form shown in Figure 2 below. The statement on the right forces the student to more systematically think about experimental factors and measuring the response to the factors.

2. Use factorial screening experiments to decide a course of action. During undergraduate labs, students normally vary one factor at a time. Rarely are they exposed to designs that allow them to vary two or more factors and analyze the impact. However, varying one factor at a time is the least efficient means of experimentation and prevents one from detecting the interaction of two factors. For example a one-factor-at-a-time experiment to evaluate three factors would require 16 replications of the experiment and does not allow the experimenter to determine if there exists interactions between the factors. A factorial experiment for the same three factors would only require 8 experimental runs and one could assess if there were interactions between the factors. Invariably, the results of the first experiment demand that the researcher design and run a second experiment. By using factorial designs, the student can reap a geometric benefit of savings. An excellent introduction to using factorial and fractional factorial designs to screen variables can be found in the article by C.D. Hendrix [13]. For those who need a statistics refresher, the book by Devore and Farnum [14] is excellent.
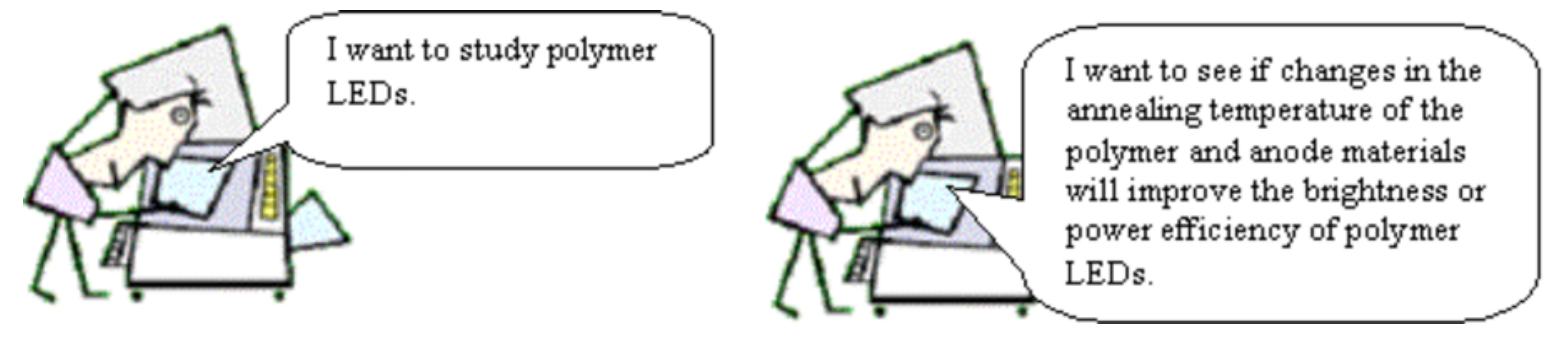

Figure 2. A statement of the problem. The statement on the left does not help the student to conduct the research. The statement on the right leads the student to devise experiments that can provide quantitative results.

\section{CONCLUSION}

In conclusion, we have presented a few observations about encouraging undergraduates to participate in effective research projects, suggesting how to select projects, define attractive projects, entice students to participate, and some tools that help students make the most out of a research experience. While some students may opt out of further research, we aim to help students learn the joys of research, to anticipate the creative and perseverant problem solving required, preparing them to accomplish useful research effectively as undergraduates and to enter graduate research programs with their eyes open. 


\section{ACKNOWLEDGEMENTS}

This material is based upon work supported by the National Science Foundation under Grant No. 9820781.

\section{REFERENCES}

1. C. W. Tang and S. A. VanSlyke, Appl. Phys. Lett., 51, 913-915 (1987).

2. J. H. Burroughes, D. D. C. Bradley, A. R. Brown, R. N. Marks, K. Mackay, R. H. Friend, P. L. Burns, and A. B. Holmes, Nature, 347, 539-541 (1990); R. H. Friend, R. W. Gymer, A. B. Holmes, J. H. Burroughes, R. N. Marks, C. Taliani, D. D. C. Bradley, D. A. Dos Santos, J. L. Brédas, M. Lögdlund \& W. R. Salaneck et al, Nature, 397, 121-128 (1999).

3. D. Braun and A. J. Heeger, Appl. Phys. Lett., 58, 1982-1984 (1991); G. Gustafsson, Y. Cao, G. M. Treacy, F. Klavetter, N. Colaneri, and A. J. Heeger, Nature, 357, 477-479 (1992); Y. Yang, MRS Bulletin, 22, 31-38 (1997).

4. Links contained in http://www.ee.calpoly.edu/ dbraun/polyelec/moreinfo.html and http://www.chipcenter.com/eexpert/dbraun/main.html accessed April 10, 2001.

5. M.D. McGehee, E.K. Miller, D. Moses and A.J. Heeger, Twenty Years of Conducting Polymers: From Fundamental Science to Applications, Advances in Synthetic Metals: Twenty Years of Progress in Science and Technology, ed. P. Bernier, S. Lefrant and G. Bidan, (Elsevier, 1999) pp. 98-205.

6. F. Wudl and G. Srdanov, U.S. Patent No. 5189136 (23 February 1993).

7. G. Yu, J. Wang, J. McElvain, and A. J. Heeger, Adv. Mater. 10 \#17, p. 1431 (1998).

8. N.S. Sariciftci, L. Smilowitz, A.J. Heeger and F. Wudl, Science 258, p. 1474 (1992);

N.S. Sariciftci and A.J. Heeger, U.S. Patent No. 5454880 (3 October 1995).

9. G. Yu, K. Pakbaz, and A.J. Heeger, Appl. Phys. Letters 64, p. 3422 (1994); G. Yu, J. Gao, J.C. Hummelen, F. Wudl and A.J. Heeger, Science 270, p. 1789 (1995); G. Yu and A.J. Heeger, J. Appl. Phys. 78, p. 4510 (1995); J.J.M. Halls, C.A. Walsh, N.C. Greenham, E.A. Marseglia, R.H. Friend, S.C. Moratti and A.B. Holmes, Nature 376, p. 498 (1995).

10. M. Cecchi, H. Smith, D. Braun, L. Vanasupa, Talk C4.5, this conference, Mater. Res. Soc. Proc. 65, in press (2001).

11. M. Lloyd, D. Braun, Poster UMRI-35, this conference (unpublished)

12. D. Braun, K. Erickson, and G. Yu, Synthetic Metals 121, pp. 1747-1748 (2001).

D. Braun, J. Rowe, and G. Yu, Synthetic Metals, 102, pp. 920-921 (1999).

13. C.D. Hendrix, Chemtech, p. 167 (1979).

14. J.L. Devore, N.R. Farnum, Applied Statistics for Engineers and Scientists (Brooks/Cole Publishing Company, Pacific Grove, California, 1999) 